ered at once. Sometimes a hot room will cause fainting. A peculiarity is that there is very little absorption about the tongue and throat, but in the nose it is very rapid. In regard to operating on the middle turbinated I think that the old way of tearing the body away with forceps is unsurgical and unsafe. The membrane continues through the cribriform plate into the cranium, and it is remarkable that serious consequences are not reported more frequently. The turbinated body can be removed neatly and effectively with the ethmoid clippers or scissors and a cold wire snare.

\section{A CLINICAL STUDY OF TWENTY-ONE THOU- SAND CASES OF DISEASES OF THE EAR, NOSE AND THROAT.}

\section{BY SETH SCOTT BISHOP, B.S., M.D., LL.D.}

Surgeon to the Illinois Charitable Eye and Ear Infirmary; Professor of tology in the Post Gractuate Medical School and Hospital; Nose. Throat and Ear in the Illinois Medical college, etc. cHICAGo.

The following statistic table of 15,300 cases, combined with a table of $\tilde{0}, 700$ cases already published, represent the records of 21,000 treated during the past seventen years at the Illinois Charitable Eye and Ear Infirmary in Chicago. The following table was compiled for me by my assistant, Dr. Charles L. Enslee.

My first classification was instituted for the purpose of establishing a basis of calculation of the influence, if any, exerted by occupation, age or sex in the causation of diseases of the ear, nose and throat.

The condition of each patient at the time he first presented himself at the clinic is presented to determine the relative frequency of the different diseases.

As is common in charity hospitals, a considerable number of those who applied for treatment belonged to that class of laboring people who have no definite trade or fixed occupation. In order to facilitate investigation and simplify the tables as far as possible, all those occupations that were closely related to each other in nature and effects were grouped under one heading. For example, under the classification of clerks were embraced salesmen, bookkeepers, office employes, etc.; with teamsters were grouped car drivers, peddlers, etc.: cooks and bakers were classified together; brass molders, iron molders, etc., were classified with iron workers; plumbers, gas and steam fitters appear together; such closely allied occupations as stone cutters, stone masons, bricklayers and plasterers in which the influences and exposures are very similar, are grouped together under the head of day laborers, a term borrowed from the laborers themselves.

The combined tables show that of the 21,000 cases there are 11,119 patients with occupations, classified under twenty-eight headings. Of this number, 3,813 had out-door work and 7,306 in-door. About 34 per cent. are out-door occupations and 66 in-door; or about twice as many in-door occupations as out-door.

The largest number of any one class were in-door workers, 3,045 domestic servants. Next in order were about half that number of the out-door class, or 1,508 day laborers. Then follow groups of the next highest numbers; 858 clerks, 460 iron workers, 452 carpenters, 400 sewing women, 378 factory workers of all kinds, all in-door occupations before we reach the out-door class again in going down the scale.

While the great stores and factories furnish a large number of patients, the homes contribute 5,615 females, including the servants, seamstresses and women without occupation, or more than one-fourth the whole number of the combined tables. These facts are significant when we take into account the slight difference between the number of males and females affected under the age of 15 years. Out of 6,162 children under 15 years of age there were 1,484 boys and 1,590 girls between the ages of 6 and 15 years; and 1,641 boys and 1,447 girls under 6 years.

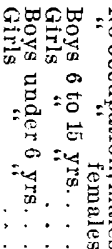

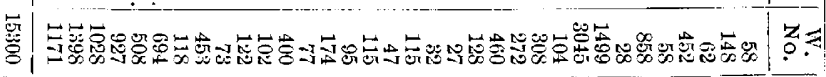

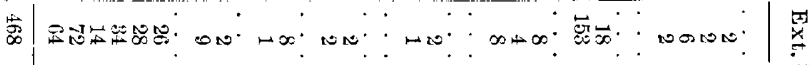

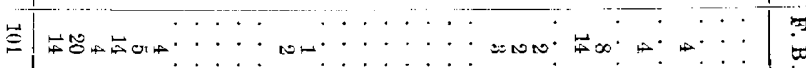

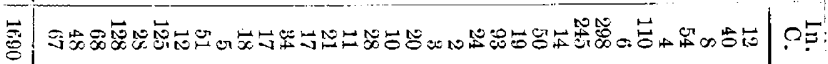
岳

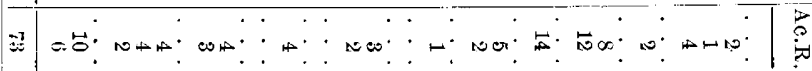

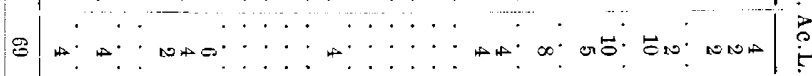

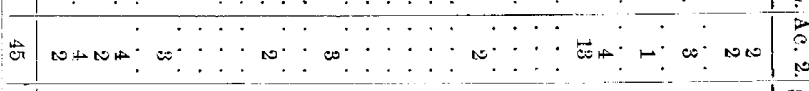

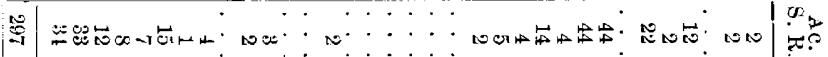

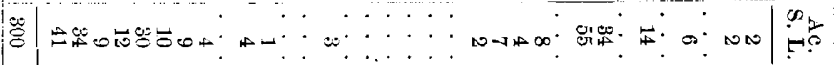

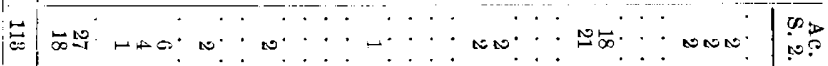

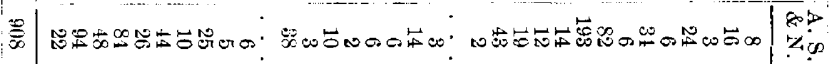

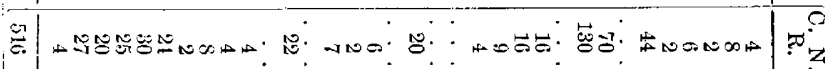

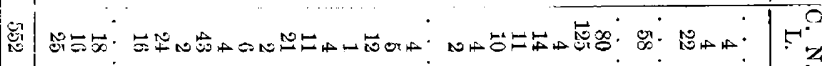

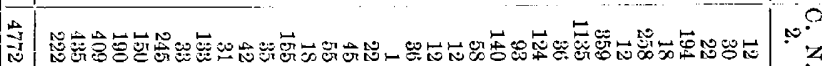

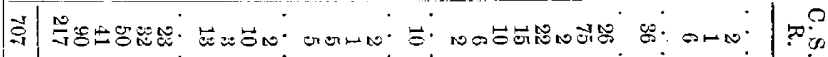

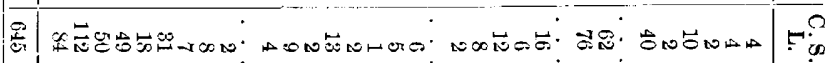

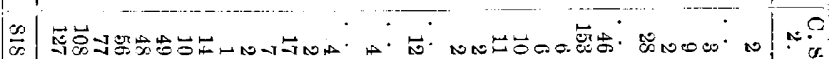

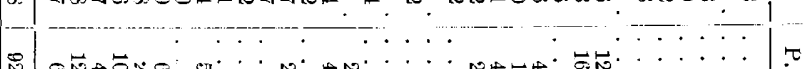

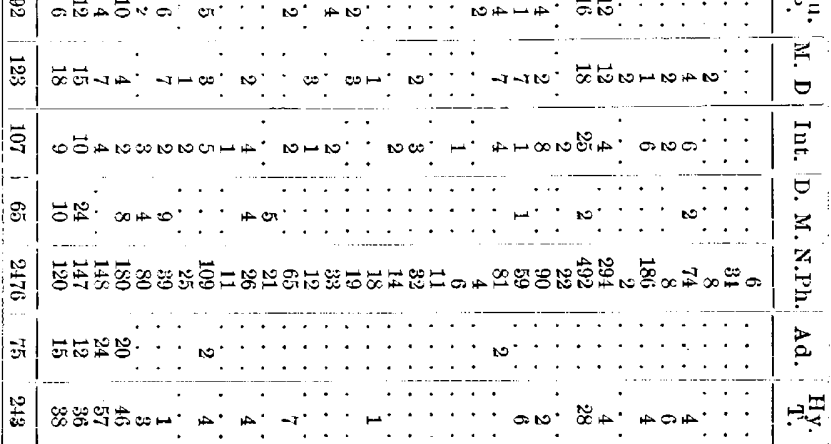
1 From the writer's forthcoming book on Diseases of the Ear, Nose 1 rrom the writer 
F. B.-foreign body.

In. C.-inspissated cerumen.

Fur.-furunele.

Ac. R.-acute inflammation of the right middle ear

Ac.

Ac. 2-acute intammation of both middle ears.

Ac. S. R.-acute suppurative inflammation of the right middle ear.

Ac. S. L.-acute suppurative inflammation of the left middle ear.

Ac. S. 2.-acute stuppurative inflammation of both middle ears.

A. S. \& N.-an acute suppurative inflammation of one middle ear with a chronic non-suppurative inflammation of the other.

C. $N$. R.-chronic non-suppurative inflammation of the right middle

ear.

ear.

C. N.

C. S. $\mathrm{R}$-chronio suppuppurative indamation

C. S. R.-chronic suppurative inflammation of the right middle ear.

C. 2 chronic suppurative inflammation of both middle ears.

Ai. I'-aural polypus.

Aiv. ${ }^{2}$-aural polypus.

Int.-diseases of the internal ear.
D. M.-deaf mutes.

N. Ph.-naso-pharyngeal catarrh.

Ad.- tdenoid growths in the vault of the pharyux.
Hy. T.- hypertrophied tonsils.

Of all these children 3,037 were girls and 3,125 boys, leaving a difference of only 88 more males than females under 15 years. Between the ages of 6 and 15 years there were 106 more girls than boys. Under 6 years there were 194 more males than females.

Sex seems to have no influence in the production or prevention of diseases of the nose, throat and ear. It appears that up to the age of 15 years both sexes suffer nearly equally. Possibly a reason for this may be found in the similarity of the lives and habits of the sexes during this early period. But the classes of society that afford clinical material at the medical charity institutions are such that necessity requires them to abandon the pursuit of an education at about the fifteenth year, and to enter upon bread-earning vocations. Thenceforth the divergence in habits and environment increases. The males are either out of doors more than before, or confined chiefly to mercan tile houses and factories. The females become domestics, clerks, shopgirls and seamstresses.

An interesting question pertains to the relative frequency of diseases of the right and of the left ear, and of diseases of one ear as compared with diseases existing coincidently in both ears. The above table shows that in acute inflammation of the middle ear there is but a very slight difference in the frequency of involvement between the two ears, and both ears were affected in 24 per cent. of all the cases. In acute suppuration of the middle ear again there is too little difference between the two ears to take into account. In 15 per cent. of all these cases both ears were involved.

In the 5,849 cases of chronic non-suppurative inflammation of the middle ear the two sides were about equally affected, but a great contrast is now offered in the relative frequency with which both ears are involved in the various middle ear diseases, for in this instance nearly 82 per cent. of all the cases presented bilateral aural affection. Sufficient importance must be attached to these undeniable figures in formulating our prognosis when only one ear is already diseased, for it follows, almost as the night the day, that if one ear has become seriously affected, especially with the sclerotic form of dry catarrh, the other becomes subject to the same destructive process.

In chronic suppurative otitis media the two ears suffer nearly equally, and it appears that both ears are simultaneously affected in a little more than 60 per cent. of the cases. In 3,149 instances of unilateral diseases of the ear, there was an excess of only 37 cases of the right over the left. This fact is mentioned particularly because the opinion has often been expressed that one ear was much oftener affected than the other, some specialists believing that the right was affected, by far, more frequently than the left ear.

The tables show that about 13 per cent. were afflicted with nasopharyngeal diseases, but the actual number would be much in excess of this figure. The Infirmary being an eye and ear hospital strictly, not as great prominence has been given to the nose and throat affections as would be desirable, this part of the diagnosis sometimes being entered on the patient's cards instead of upon the record books.

About 0.8 per cent. had diseases of the mastoid process, which was nearly twice as prevalent in males as in females.

Deaf mutes formed about 0.5 per cent. of the 21,000 cases. There were three times as many males as females.

The largest number of any one class of diseases were 8,805 with chronic non-suppurative inflammatory processes of the middle ear, or 42 per cent. of the whole number. Next in numerical order come 3,664 cases of chronic suppurative inflammation, or 17 per cent; and the next highest number, 1,010 cases of acute suppuration, or 5 per cent.

Children under 15 years of age constitute about 29 per cent., or more than one-fourth of the whole number of cases. Very many of them dated back to attacks of scarlet fever, measles and the earaches, and "running ears" of infancy, so that a much larger percentage than appears should probably be credited to the period of childhood. Only a small proportion of the children were brought for treatment during the acute stage of inflammation. Only about 10 per cent. were acute cases, leaving 90 per cent., or nine times as many who had not applied for treatment until the inflammation had reached a chronic stage. Indeed, only 13 per cent. of the adults were seen in the acute stage of their troubles.

Columbus Memorial Building.

\section{ELECTROLYSIS IN THE TREATMENT OF DETACHED RETINA.}

Read in the Section on Ophthalmology, at the Forty-seventh Annual Meeting of the American Medical Association, held at Atlanta, Ga., May 5-8, 1896.

BY W. T. MONTGOMERY, M.D. CHICAGO, ILL.

Within the past few years various remedial agents: have been advocated with more or less enthusiasm in the treatment of detachment of the retina. One of the more recent of these agents, and one which from its action and the nature of the disease seemed to promise as much or more than any other treatment, is electrolysis. One of the most full and encouraging reports on the application of electrolysis in detachment of the retina, is by Dr. Terson, and was published in the last July number of the Annales d'Oculistique. Dr. Terson reports twelve cases treated with one recovery which had lasted nine months, and five improvements which had persisted for from two to nine months. Within the last six months four cases of detachment of the retina have been treated in the Illinois Charitable Eye and Ear Infirmary, two by myself and two by Dr. B. Bettman. In the treatment of these cases we, in the main, followed the recommendations of Dr. Terson. Positive electrolysis was used; the eye was punctured by the strong platiniridium needle at some point of the sclerotic corresponding to the detach- 